\title{
Serebral palsi ve iş hayatı (yaşamdan hikâyeler)
}

\author{
Cerebral palsy and work life (stories from life)
}

\author{
Emre Çullu
}

Aydın Adnan Menderes Üniversitesi Tıp Fakültesi Hastanesi, Ortopedi ve Travmatoloji Ana Bilim Dalı, Aydın

\begin{abstract}
Sağlık çalışanları, serebral palsili bireylerle görevleri gereği, saatlerini, günlerini, aylarını beraber geçirirler. Hastalarına en iyi hizmeti vermek için çaba gösterirler. Kaba motor işlev sınıflama sistem düzeyi (KMiSS, GMFCS) I, II ve III olan bireylerin topluma katılmaları beklenir. Yaşam beklentileri normal bireylere yakındır. Sağlık çalışanı, tedavi süreleri dışında empati yeteneğiyle uyumlu olarak serebral palsili bireyin yaşadığı zorluklardan haberdar olur. Bu yazıda yoğun çalışma temposunda bazen göz ardı edilebilen serebral palsili bireylerin yaşamlarına göz atıldı. Iş̧lev bozukluklarının yaşamda, iş yerlerinde yarattığı zorluklara kulak vermek amacıyla KMiSS düzey II ve III olan üç serebral palsili bireyin, tedavi süresince yaşadıklarına, ev ve iş yerlerindeki zorluklara kendi ifadeleriyle yer verildi.
\end{abstract}

Anahtar sözcükler: serebral palsi; yaşam; iş yaşamı
Healthcare workers spend hours, days, and months together with individuals with cerebral palsy. They strive to provide the best service to their patients. Individuals with gross motor function classification system level (GMFCS) I, II and III are expected to participate in society. Life expectancy is close to normal individuals. Apart from the duration of treatment, the healthcare workers become aware of the difficulties experienced by the individual with cerebral palsy in accordance with the ability to empathize. In this article, the lives of individuals with cerebral palsy which can sometimes be ignored at a busy working pace, were looked at. In order to listen to the difficulties that dysfunctions create in life and in the workplace, three individuals with cerebral palsy with GMFCS level II and III experienced during treatment and difficulties in their homes and workplaces were included in their own words.

Key words: cerebral palsy; life; work life ağlık çalışanları, işlerinin gereği insan sağlığı için özverili bir çalışma yoğunluğu içerisindedirler. Serebral palsili hastaların tedavisi, bu zorluğa ek olarak ekip oluşturulmasını gerektirir. Ekip çalışması, serebral palsili çocukların tedavisinde daha başarılı sonuçlar alınmasını sağlar. ${ }^{[1,2]}$ Ekipte yer alan sağlık çalışanları olarak fizik tedavi hekimi, ortopedi ve travmatoloji uzmanı, çocuk nöroloğu, fizyoterapist, psikiyatrist, psikolog vb. görevleri gereği hastanın yaşamında belli süreler yer alırlar ve hizmet verirler. Serebral palsili birey hayatın devamında yalnızdır ve hastalığının yarattığı işlev bozukluğu ile başa çıkmak zorundadır. Bu zorluklar bazen fiziksel bazen duygusal bazen de her ikisi olabilir. Hayatın erken dönemlerinde var olan aile desteği, anne babanın yaşlanması ve bireyin büyüyüp ağırlaşması ile daha da zorlaşır. Kaba motor işlev sınıflama sistem düzeyi (KMiSS, GMFCS) I, II ve III olan bireyler toplumda yer alıp hayatlarını kendi başlarına sürdürebilirler. ${ }^{[3-5]}$ Motor bozukluğu az olan serebral palsili bireylerin yaşam beklentisi normal popülasyona yakındır. ${ }^{[6]}$ Sağlık çalışanları, görevleri gereği bireyin yaşamında tedavileri sırasında saatlerini, günlerini, aylarını beraber geçirirler. Sağlık çalışanı, empati yeteneğiyle uyumlu olarak serebral palsili bireyin yaşamı konusunda bilgi sahibi olur. Bu yazıda işlev bozukluklarının yaşamda, iş yerlerinde yarattığı zorluklara kulak vermek amacıyla KMiSS düzey II ve III olan üç serebral palsili bireyin tedavi süresince yaşadıklarına, ev ve iş yerlerindeki zorluklara kendi ifadeleriyle yer verildi. İlk iki serüvende KMisS düzey III tutulumlu devlet memuru, üçüncü serüvende ise KMiSS düzey II tutulumlu bir ev hanımının mektubu yer almaktadır. Mektuplardan özel isimler çıkarılmıştır.

- İletişim adresi: Prof. Dr. Emre Çullu, Aydın Adnan Menderes Üniversitesi Tıp Fakültesi Hastanesi, Ortopedi ve Travmatoloji Ana Bilim Dalı, Aydın, Türkiye Tel: 0532 - 4560046 e-posta: ecullu@superonline.com

- Geliş tarihi: 21 Mart $2021 \quad$ Kabul tarihi: 28 Mart 2021 


\section{Serebral Palsili Bir Devlet Memurunun İş Yaşamı}

Herkese merhaba, ben yirmi beş yaşında serebral palsili bir bireyim. Beş yılı aşkın bir süredir kamu sektöründe çalışıyorum. Size beş yıllık bu süreçte nasıl zorluklarla karşılaştığımı, özel ve kamu sektörünün bu konudaki eksiklerinin neler olduğunu, nasıl bir iyileştirme yapılırsa biz engelliler için daha verimli ve erişebilir çalışma ortamları oluşturulabilir, biraz bundan bahsedeceğim.

Benim işe başlama saatim 08:00. Hemen hemen bir çoğumuz gibi hazırlanmak, kahvaltı yapmak ve tuvalet ihtiyacımızı görmek sağlıklı bir bireye göre çok daha uzun sürüyor. Çoğu çalıştığımız ortam ihtiyaçlarımıza uygun olmadığından hazırlanırken evde daha fazla zaman harcıyoruz. Bazı engelli arkadaşlarım, fiziksel durumu sebebi ile, tuvalet ihtiyacını sadece evlerinde rahat görebiliyorlar. Bunları göz önünde bulundurduğunuzda, işe başlama saatlerinin yeniden düzenlenmesi gerekiyor.

Benim çalıştığım bina yeni ve engellilere uygun bir bina. Işse başlarken durumumdan ötürü eve olan uzaklığa bakmadan burada çalışmak için tercih yaptım. Tekerlekli sandalye kullandığım için rampası, asansörü, engelli tuvaletleri var mı (?) vs. gibi koşullarını düşündüm. Ama kamunun birçok binası ve özel sektörde işyerleri hala engelliler için uygun değil ve bu konuda herhangi bir adım atılmıyor. Teknoloji ve akıllı sistemlerle düzenlemeler var iken, çalışma hayatına bu kadar özel gereksinimi olan birey katılmış ve sorunlar yaşıyorken, engelsiz dönüşüme geç kalınmadı mı?

Bir başka konu da tedavilerimiz için izin konusu. Benim ve birçok serebral palsili arkadaşımın fiziksel sağlı̆̆ının iyiye gitmesi ve mevcut kazanımların korunması, hayat kalitemizin artışı gibi noktalarda, fizik tedavi en temel ihtiyacımızdan biri. Işse başladıktan sonra birçok arkadaşımın tedavileri için işyerinden izin almakta zorlandıklarını biliyorum. Ben bu konuda anlayışlı bir amir ile çalışıyorum ama başka bir amir bu kadar yardımc olmayabilir. Bu konu tamamen amirlerin ve işverenlerin inisiyatifine bırakılmış. Fizik tedavi, bizler için süreklilik gerektiren, sağlığımız için daha önce de söylediğim gibi en temel noktadadır. Talep ettiğimiz izin için çerçeveleri belli olan bir düzenleme gerekmektedir.

Engelimiz olsun veya olmasın hepimiz iş hayatımız ile ilgili beklenti içine gireriz. Benim ilk iş deneyimim kamuda başlamam ile olmuştu. Hayaller kuruldu planlar yapıldı ve evet bu planları gerçekleştiriyor da insan. Ama bir konuda zaman biraz ağır işliyor. Biz engelliler sosyal hayata daha da geç dâhil oluyoruz. Iş hayatının dinamiklerine alışıyoruz. Erken kalkıp erken yatıyoruz. Hepsi bir anda geliyor, zamanla duruma hem fiziksel olarak hem de mental olarak uyum sağlıyoruz. Anne ve babalara tavsiyem, eğer engelli bir evlat sahibi ise ve işe başlamışsa biraz daha bu yeni işe başlama sürecini yakın takibe alsınlar. Çünkü bu süreç bizler için daha zor olabiliyor. Ama iletişim ve çözüm odaklı olduğunuz sürece her şeyin üstesinden gelebilirsiniz, bana inanın.
Bu yazıyı çok değer verdiğim biri yazmamı benden rica edene kadar inanın bu kadar ayrıntılı düşünmemiştim. Sonra hayatımın genelinde yaşadığım zorlukları düşündüm ve ne kadar zor bir hayata adapte olmuşum. Çoğu zorluğu artık göz bile görmez olmuş, kanıksamışım. Umarım siz de bu zorlukları detaylıca düşünüyor olursunuz. Sağlıcakla kalın.

\section{Serebral Palsili Bir Üniversite Personelinin Serüveni}

Her şey ilk adımı atmamla başlamıştı. Aslında atamamamla. Ben 5 buçuk aylık 750 gram dünyaya geldim. Mucizelere yeni başlıyorduk. Buraya kadar her şey normal. Her şey 3 aylık kuvöz serüvenimle başlıyor. Aslında burada her şey başlamıyor, bitiyor. Bebekliğim hiç normal olmadı. Hastane ve doktor odalarında başladı hayat hikâyem. Her çaldığımız kapı umutsuzdu ve hep aynı cümleyi duyuyorduk. Bu ilk gerçekçi cümlemizdi: "Bu çocuk yürüyemez." Hayat bu. Her şey kötü olsa da hayatınızda karşınıza büyük sürprizler çıkabilir. Benim de öyle oldu. Ortopedi ve travmatoloji uzmanı doktorumla dört yaşında karşılaştım. Yürüme hayalim burada başladı. Her şeyi santim santim, ölçerek başardık. Altı yaşında ilk büyük operasyonumu gerçekleştirdik. Artık destekli de olsa adım atmayı başarmıştım. Doktorum beni her şeyi başarabileceğime inandırmıştı. Arkadaşlarım beni görünceye kadar bu inanmışlık devam etmişti. Anaokulu öğretmenim sayesinde ilk silinmeyecek acı gerçeği öğrenmiştim. "Engelli çocuk okumaz!" Bu kelime hayatımın sonuna kadar bana eşlik edecekti.

Doktorlarım sayesinde üç gün egzersiz, iki gün okulla bu tabuları yıkıyordum. Gerçekleri görmeye yeni başlıyordum. ilkokuldaki arkadaşlarımın tabiriyle sakattım, dışlandım, hor görüldüm. Kendi kabuğuma çekildim. Kimse benimle oyun oynamıyordu. Sanki hastalığım bulaşıcıydı. Hâlbuki ben öyle olmayı istememiştim. Onlar beden eğitimi dersinde koşarken bense kendime saklanacak yer aradım. Onlar gibi koşamadım, top oynayamadım. Hep eksik hep yarım olmaya başladığımı anlamıştım artık. Herkes tarafından başarısız, aciz ve hayatta hiçbir şey beceremeyen biriydim. ilkokulda, destekli de olsa sekiz sene boyunca beş kez dışarı çıkabilmiştim. Dışarı çıkmak diğerleri için ne kadar basitse benim için bir o kadar meşakkatliydi.

Artık yaşım ilerledikçe engelli kelimesi beynimde kalıplaşıyor ve kendimi daha çok sorgulamaya başlıyordum. "Neden ben? Niye ben? Ben olmamalıydı. Başkaları olmalıydı" Içimden sürekli geçirdiğim cümlelerimdi bunlar benim: toplum tarafindan benimsenmemek ve kabullenememek. Ikinci ameliyatımdan önce daha çok acıyan gözlerle bakılmıştım. Ama ben kendi içimde bir seviye daha yükselmiştim. Her ameliyat benim için bir umut, bir başlangıçtı. Normal çocuklar bisiklet sürerken ben soğuk ameliyat odalarının kokusunu içime çekiyordum. Bu, beni kendi kabuğuma daha da soktu. Yine her şey başa dönüyordu. Her değişik yer, her değişik insan ve ben engelliyim demek daha da acı veriyordu. Artık engelli olduğum yüzüme vurulsa da, bazı yerlerde destekli 
de gitsem, içimde hep bir umut vardı. Bazı insanların bakış açısını değiştiremezsiniz. Lise hayatımda buna bir örnektir. "Üniversite okuyacak diye beklemeyin, okuyamaz, çalısır diye beklemeyin çalışamaz". Herkesin kazanamaz dediği üniversiteyi kazandım ve zor olsa da çalısma hayatına atıldım. Başardım.

Hayat hikâyemin başladığı, doğduğum ve hayat mücadelemi verdiğim kurumda (Xxxxx Üniversite Hastanesi) çalışmaya başlamıştım. Illk defa yalnız kalmıştım. Artık bundan sonra dimdik yürümem gerekti. Ben de normal insanlar gibi işime gelip gidiyordum. Bir an engelli olduğumu unutmuştum. Ta ki düşmelerim başlayıncaya kadar. Artık insanların bakışlarından yorulmuştum. Herkes için acayip olan, engelli çalışandım. Bu cümleler beynimde kalıplaşmaya başladıve bu cümleler beni hep geriye itti. "Ya tekrar düşersem! Insanlar bakarsa, gülerlerse!” Baktılar ve güldüler de. Yaşım 24 ve ben, desteksiz dışarı çıkamayan, durağa tek başına gidemeyen, en ufak bir şeyde düşen, karşıdan karşıya geçemeyen, herkesin baktığı ve engelli dediği çalışanım. Herkesin klasik cümlesi: "Tekerlekli sandalye almalısın." Toplumun her zaman bir fikri var sadece. Toplum tarafindan sen de yaparsın cümlesini hiç duymadım. Hep düşünürüm bu insanlar bu kaldırımdan nasıl çıkıyor diye. Belki ben de çıkarım bir gün diyorum ama olmuyor. Dünyadaki en şanslı insan, desteksiz kaldırımlara çıkan, dışarıya çıkan, hiçbir ele ihtiyaç duymadan sokaklarda tek başına dolaşan insanlar bence.

ilk hayalim, dimdik ayakta durabilmek, desteksiz tek başına kaldırıma çıkmak, bisiklet sürmek, karşıdan karşıya geçebilmek. Bu hayallerin gerçek olmasını umut ediyorum. ENGELLi olduğum gerçeği değişmeyecek, bunu biliyorum. Ama kabullenmekle yolun yarısını aştığıma inanıyorum.

Kendi kendime ayakları üstünde duran biriyim diyemiyorum. Çünkü her zaman birilerine ihtiyaç duyacă̆ımı biliyorum. Engelli bir birey olduğum için karamsar ve umutsuzum ama her zaman bana en üst seviyelere çıkacağımı söyleyen, desteğini her zaman hissettiren ve bu umudumu sürekli tazeleyen doktorlarıma teşekkürü bir borç bilirim.

\section{Serebral Palsili Bir Ev Hanımının Serüveni}

Aydın'ın bir köyünde 1993 senesinde, üç çocuklu bir ailenin dördüncü ve son çocuğu olarak altı aylık dünya gelmişim. Bir ay Xxxxx Hastanesinde kuvözde kalmışım. Bir ayın sonunda küçük olmam dışında hiçbir sıkıntı yokmuş. O zamanlar 13 yaşında olan ablam, annem ve babaannem sayesinde kendimi toplamışım. Ancak 2 - 3 yaş arasında yürüme konusunda sıkıntı yaşamaya başlamışım. Illk olarak Xxxxx Hastanesinde tedaviye başlanmış. Orada serebral palsi tanısı konmuş. Tanı sonucunda aileme yapılan ilk açıklamada beynimde herhangi bir rahatsızlık olmadığı sadece bacaklarımdan rahatsız olduğum söylenmiş. Nisan 1993'te başlamış olduğum hayat ile hem benim için hem de doğumundan bu yaşıma kadar sevgilerini eksik etmeyen ailem için bir savaş başlamış oldu. Ameliyat savaşım ilk olarak üç yaşımdan sonra kasık ve topuk arkasından başlamış. Daha ilk ameliyatımda, bilinçaltıma, annemin kokusunun yanına alçı kokusu yerleşti. Mahallede koşan çocukların yanında benim devamlı yatakta yatıyor olmam çok can sıkıcı idi. Ama ailem içine kapanmamam ve canımın sıkılmaması için ellerinden geleni yaptılar.

Tam o sert ağır alçılardan kurtuldum derken hayatım boyunca hiç bitmeyecek fizik tedavi süreci başladı. Bu süreçte canım o kadar acıyordu ki üç yaşına bir çocuğun kaldırabileceği acılar değildi. Tabi bu acıların, ileriki hayatımda bana azim ve kararlılık gibi özellikler kazandıracağını tahmin edemezdim. Yaşadığım zorluklardan olacak ki, o zamanlardan beri hiç sevemedim fizik tedaviyi. Şimdi düşünüyorum da fizyoterapist ablalarım ve abilerim belki onlar için küçük ama benim için büyük sürprizler yaparlar ve hediyeler verirlerdi. Bir aylık fizik tedavi sürecinden sonra evde yapmamız gereken hareketleri yapmama yardımcı olan annem ve aileme çok nazlanmıştım "canım acıyor" diyerek. Tabi ailem de kıyamazdı bana, ara verirdik hemen. Bana hiç hissettirmeseler de ilk dönemler eminim ailem için de zor olmuştur. Sonuçta fizik tedavinin ne olduğunu tam bilmiyorlardı. Ailem de, benimle birlikte bazı şeyleri öğrendi.

Evet, yıl 1999 ve ben altı yaşında tam sokaktan eve girmeyecek yaştayım ama ne kadar yürüyüp oynasam da kısa zamanlı ayakta durabiliyordum. İşte benim dönüm noktası olan bu yıla, hastanede çalışan akrabam sayesinde yeni ortopedi ve travmatoloji uzmanı doktorum ile tanıştım ve benim yeni maceram başlamış oldu. Doktorumun ilk muayenesinde çıkan sonuç önceki ameliyatlarımın tekrarlanması gerektiğiydi. Doktorumdan almış olduğu o anki güven duygusuyla tekrar ameliyatlarımı yapılması kararı alınmış ve doktorum benim de fikrimi sormadan ameliyat tarihini vermemişti. Ameliyat savaşım yeniden başladığı zaman mavi önlük giyip okula gitmem gerekirken şansıma, yine yeşil önlük çıktı. Okul kantininden içmem gereken meyve suyunu hastane odasında narkozlu meyve suyu içip ameliyathaneye girmek oldu. Doktorumun sesiyle yarı uyanık yarı uykulu bir halde havada büyük lambalar ve soğuk bir oda hocamızın eliyle iki yapıp bu kaç dediği daha dün gibi aklımda. Tekrar uyandığımda odama gelmişim, etrafimda ailem ve sevdiklerim vardı. O zamanlardan hatırladığım bir kesitte şu idi. Yine sevmediğim alçı ayağımda idi.

Ameliyat yerlerim iyileştikten sonra yine bir aylık fizik tedavi sürecim başladı annem beni net bir şekilde yürümediğim için sırtında fizik tedaviye götürüp getirmeye başladı. Bir ayın sonunda arkadaşlarımın okul telaşını görünce ben de anneme ben ne zaman okula gideceğim demeye başladım. Annem ve babam benim üzülmemi istemedikleri için yaşımın okul için daha küçük olduğuna ve seneye gideceğime ikna etmeye çaIışıorlardı. Ama ben okul yaşında olduğumu biliyordum. O şartlar altında çok da yapılacak bir şey yoktu. Okul hevesim bir sonraki seneye kalmıştı. Ameliyattan sonra içe dönük olan ayaklarım düzelmişti ve bir nebze olsun rahat yürüyebiliyordum. Bu süreçte kontrollerime devam ediyorduk. Bir süre 
sonra doktorum diz kapaklarımın arkasından da ameliyat olmamı gerektiğini söyledi. Okula başladığım için okulum aksayacağından, tereddüdüm vardı. Bu yüzden, ben yaz tatilinde olmak istediğimi söyledim. Doktorum, on beş tatilinde yapılması yönünde beni ikna etti. O gün geldi, ameliyatımı oldum. Daha sonra annemle tekrar fizik tedaviye gidip gelmeye başladık. Fizik tedavinin olmadığı günlerde annem beni okula götürüyordu. Bir aylık fizik tedavi sonunda yavaş, yavaş normal hayatıma ve kendi ayaklarımın üzerinde rahatça yürümeye başladım.

Belli aralıklarla doktorumla kontrollerim devam ediyordu. Yıllar böyle geçerken yaşım 14 oldu ve doktorum bacak üstü ameliyat olursam benim için iyi olacağını söyledi. Ne kadar korksam da ameliyatımı oldum. Ameliyat sürecinde ve sonrasında, okul hayatımı kısa süreliğine ara vermek zorunda kaldım. Bu süreçte evde kendi imkânlarım ve arkadaşlarımın notları sayesinde yattığım yerden ders çalıştım. Ameliyat sürecim bitiğinde özel bir fizik tedavi merkezinde fizik tedaviye başladım, bir yandan lise eğitimim başlamıştı.

Hayatıma bu şekilde devam edip ailemin karşı çıkmasına rağmen iki yıllık üniversiteye eğitimi de aldım. Üstelik il dışında, ailem olmadan tek başıma hayat mücadelem devam etti. Okulum bitip ve evime döndüğ̈̈mde, iş bulmak için çok çaba harcadım ama sürekli bir iş bulamadım.

Eşim 2017 yılında karşıma çıktı. Evlilik hiç aklımda yokken ikna edip beni nikâh masasına oturttu. Ne tesadüftür ki eşim ile aynı doktora gidiyormuşuz. Ben hatırlamıyorum ama yıllar önce doktorumun polikliniğinde beni gördügünü söylemesine çok şaşırmıştım. Bir söz var ya, hayat sen bir plan yaparken başına gelenlerdir diye, evlilik hayatım benim için böyle başladı. Evlenip Marmaris'e yerleştik. Bir gün hamile olduğumu öğrendim ve o andan itibaren eşim ve benim korkularımız başladı. Engelli bireyler olarak biz evladımıza nasıl bakacăğz? Bu arada doktor kontrollerimiz devam ediyordu. ikimizin aileleri de aynı korkuları yaşıyorlardı.

Bir akşam eşimi karşıma alıp "Cenabı Rabbimden ümit kesilmez. Seninle nasıl kendi ayaklarımız üstünde evlenip bir yuva kurduysak, evladımıza da aynı şekilde kendimiz bakacağı”" dedim. Doğum zamanı geldi ve hastaneye kendi ayaklarım üstünde yürüyerek gittim. Şu an 1,5 yaşında olan, dünyalar tatlısı bir oğlum oldu. Kırk günlük süreç ailelerimizin desteğiyle geçti. Daha sonra eşimin işte olduğu zamanlarda ben oğlumla evde tek başıma devam ettim. Zor yanları oldu mu? Evet. Rahat hareket edemediğim için oğlumu çoğu zaman istedim gibi kucaklayamadım, ama önemli olan istemek. ilk başta dediğim gibi, insan hayata karşı nasıl savaşması gerektiğini kendi ögrrenir. Bir de hayat arkadaşınız olarak sizin için iyi olanı bulabilmek çok önemli. Eşim, yeri geldi benim için temizlik yaptı. Yeri geldi benim temel ihtiyaçlarımı karşılamak için çaba sarfetti. Cenabı Rabbimden herkesin gönlüne göre verir sözü o kadar doğru ki. Şu an evde hiç kimseden destek almadan oğlumu büyütüyorum. Oğlumun ihtiyaçlarını sadece eşim ve ben karşılayabiliyoruz.

\section{KAYNAKLAR}

1. Louwers A, Warnink-Kavelaars J, Obdeijn M, Kreulen M, Nollet F, Beelen A. Effects of Upper-Extremity Surgery on Manual Performance of Children and Adolescents with Cerebral Palsy: A Multidisciplinary Approach Using Shared Decision-Making. J Bone Joint Surg Am 2018;100:1416-22. Crossref

2. Patel DR, Neelakantan M, Pandher K, MerrickJ. Cerebral palsy in children: a clinical overview. Transl Pediatr 2020;9(Suppl 1):S125-35. Crossref

3. Palisano R, Rosenbaum P, Walter S, Russell D, Wood E, Galuppi B. Development and reliability of a system to classify gross motor function in children with cerebral palsy. Dev Med Child Neurol 1997;39:214-23. Crossref

4. Rosenbaum PL, Palisano RJ, Bartlett DJ, Galuppi BE, Russell DJ. Development of the Gross Motor Function Classification System for cerebral palsy. Dev Med Child Neurol 2008;50:249-53. Crossref

5. El Ö, Baydar M, Berk H, Peker Ö, Koşay C, Demiral Y. Interobserver reliability of the Turkish version of the expanded and revised gross motor function classification system. Disabil Rehabil 2012;34:1030-3. Crossref

6. Himmelmann K, Sundh V. Survival with cerebral palsy over five decades in western Sweden. Dev Med Child Neurol 2015;57:762-7. Crossref 